\title{
A systematic study on the recent crisis in public health in Kerala
}

\author{
Saptashwa Datta*
}

Department of Genetic Engineering, School of Bioengineering, SRM Institute of Science and Technology, Kattankulathur, Tamil Nadu, India

\section{Correspondence}

Saptashwa Datta, Department of Genetic Engineering, School of Bioengineering, SRM Institute of Science and Technology, Kattankulathur, Tamil Nadu, India

Email: saptashwada.abc@gmail.com History

- Received: 2018-12-10

- Accepted: 2018-12-31

- Published: 2019-01-07

DOI :

https://doi.org/10.15419/ajhs.v5i1.444

\section{Check for updates}

\section{Copyright}

( ) Biomedpress. This is an openaccess article distributed under the terms of the Creative Commons Attribution 4.0 International license.

\begin{abstract}
Introduction: The state of Kerala in the country of India has been getting on the wrong side of nature over the past few years. From raging floods to massive outbreaks of viral diseases, the state of Kerala has been in turmoil over the past few years. The rains and floods have ceased leaving behind a catastrophic world of copious vector-borne infectious diseases. Moreover, a migrant crisis has been looming over the state for the past few decades resulting in an accumulation of various other dangerous diseases from multiple different parts of the country. Even after taking into consideration the great health care facilities in Kerala there have been multiple reports of infectious disease outbreaks, especially in rural districts. This short review is written with the purpose to review the facts into a single entity that can provide solid proof and hence evoke a stricter sense of awareness among communities to minimize the losses and prevent the exigency of public health that can occur not too far away in the foreseeable future. Methods: Various databases were searched like Scopus and Google scholar and all articles related to reported infections in the state of Kerala and the factors which can lead to the public health crisis were selected and included in the review. Results: A multiple numbers of articles on viral infections were obtained in the various databases. Most of the bacterial infections were reported as urinary and respiratory tract infections. Migrant crisis and 2018 floods were two of the most recent contributing factors that can lead to an emergency in public health in the state. Conclusion: There can be a sudden unexpected outbreak of infectious diseases if the government does not carefully monitor the rural districts like Alappuzha. Key words: Kerala, Floods, Vector-borne infectious diseases, Public health, Awareness
\end{abstract}

\section{INTRODUCTION}

Kerala is a state that is present in the extreme southwestern part of the nation India. Kerala is known for its high literacy rates and its vibrant culture. However, over the recent few years, it has been the hub of a myriad of natural calamities ranging from biological to meteorological. Although it has been under the temporary radar of news channels and other forms of media, the lack of long-term follow-up of the effects of these natural calamities has not been done. Over the last few years, a very minute amount of studies has been performed on the infectious disease epidemiology of the state as seen by Scopus metrics Figure 1.

\section{Viral diseases in Kerala reported over the} past five years

The viral diseases that have been reported over the past five years in the Scopus database include Nipah virus, Influenza, Hepatitis B, Respiratory syncytial virus, West Nile Virus, Japanese encephalitis virus, Kyanasur forest disease virus, coxsackievirus type B3, Chikungunya virus, Human Adenovirus, Measles virus, Hepatitis A virus and Dengue virus.

\section{Nipah Virus}

The disease which received the heaviest amount of global attention over the past few years has been a viral disease called the Nipah Virus disease. Nipah virus disease is caused by the zoonotic vector-borne RNA virus Nipah which belongs to the genus Henipavirus of the family Paramyxoviridae. This virus is spread by fruit bats belonging to the genus Pteropus of the family Pteropidae. Moreover, this disease is also highly infectious and can be transmitted both interspecifically and intraspecifically via both direct and indirect contact like saliva, urine, and other bodily secretions. There is no cure or vaccination available for the disease $^{1}$.

Recently there have been many reports about the prevalence of the virus in the state of Kerala in the month of May of 2018. The mortality rate of the virus has been observed to be very high ${ }^{2}$.

\section{Influenza Virus}

Influenza viruses are negative-strand RNA viruses which belong to the family Orthomyxoviridae. Out of the five genera of this family Influenza A virus is transmitted via zoonotic vectors and is the reason for the multiple epidemics ${ }^{3}$. 


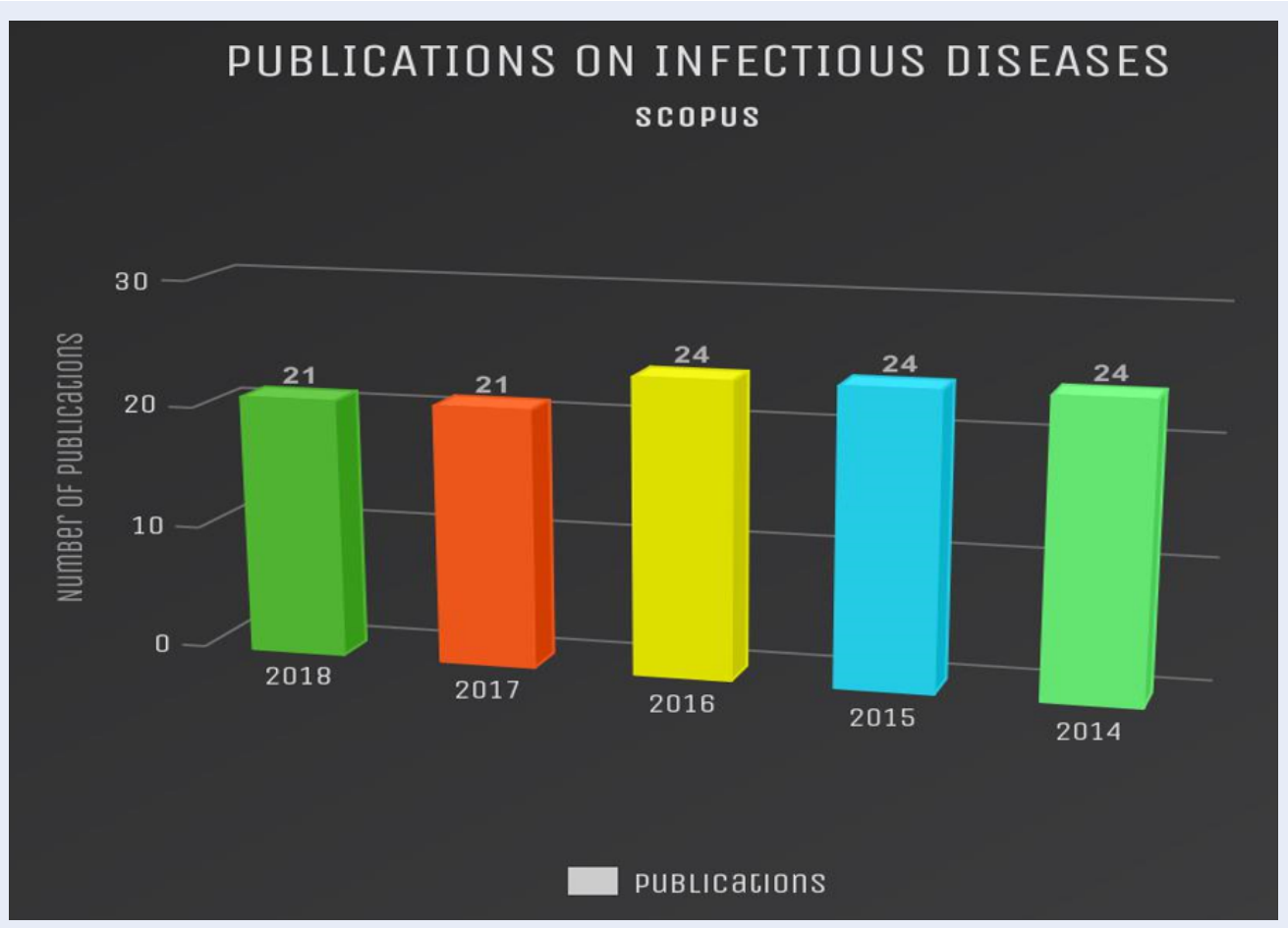

Figure 1: The number of publications on infectious diseases in Kerala (2014-18).

In Kerala, there have been reports of avian influenza outbreaks (which affect humans too ${ }^{4}$. The outbreaks have also been associated with huge economic losses ${ }^{5}$.

\section{Hepatitis B Virus}

Hepatitis B is an enveloped partially double-stranded DNA virus or in other words, it is a double-stranded DNA virus which forms an RNA intermediate during replication. The viral infections have now been brought under control with the help of Immunomodulators and antiviral medicine ${ }^{6}$.

Hepatitis B was considered to be a sexually transmitted disease; however latest research on it suggests that Hepatitis B can be transferred by nail clippings and nail cutters ${ }^{7}$.

A survey along with a study across 59 households in a rural Ernakulam district of Kerala showed 59 people (mostly above the age of 50) were affected with Hepatitis B. All patients claim to have been bitten multiple times by insects belonging to Tabanidae family and there is a possibility of these insects acting as vectors for transmission ${ }^{8}$.

\section{Respiratory Syncytial Virus}

A negative single-stranded enveloped RNA virus belonging to Paromyxoviridae family is Respiratory syn- cytial virus. It is mainly notorious for causing bronchiolitis in Infants. There has been a trial vaccine going on the rounds by the Novavax company of USA and can be helpful to prevent Respiratory Syncytial Virus infections in infants by immunization of the mother ${ }^{9,10}$.

Direct transmission by touching, transmission by potential fomites and transmission via droplets are the suggested mode of transmission by various studies ${ }^{11}$. In the study of 130 patients having acute lower respiratory tract infections, 49 were observed to be affected by the respiratory syncytial virus. After genotyping, it was found out that 32 belonged to Respiratory syncytial virus $A$ and 17 belonged to respiratory syncytial virus $B$. This study showed the prevalence of both the strains of the virus in Kerala ${ }^{12}$.

\section{West Nile Virus}

West Nile Virus is a positive single-stranded RNA virus from the Flaviviridae family of viruses. These viruses are transmitted to humans via mosquitoes of the genus Culex ${ }^{13}$.

There had been many reported outbreaks of acute encephalitis reported in Alappuzha district of Kerala and upon subsequent serological tests, the prevalence of antibodies against West Nile virus was found in 
many of the people ${ }^{14}$. In 2011 there were reports of encephalitis outbreaks in Kerala attributed to the West Nile virus ${ }^{15}$. A follow-up study shows the long-lasting damage inflicted upon the patients who survived the outbreak $^{16}$.

\section{Japanese encephalitis virus}

Japanese encephalitis virus is a positive singlestranded enveloped RNA virus belonging to the Flaviviridae family ${ }^{17}$. It is a zoonotic disease spread by mosquitoes of the genus Culex ${ }^{18}$.

Prevalence of antibodies against Japanese encephalitis virus was found in people of the district of Alappuzha in Kerala ${ }^{14}$.

\section{Kyanasur forest disease virus}

Kyanasur forest disease virus is a positive singlestranded enveloped flavivirus with an icosahedral capsid. It is a zoonotic virus spread by the tick Haemaphysalis spinigera.

A lot of individuals affected with this virus have been reported in the Wayanad and Malappuram districts of Kerala. This causes severe hemorrhagic fever with various neurological disorders ${ }^{19}$.

\section{Coxsackievirus type B3}

Coxsackievirus type B3 is a single-stranded RNA Enterovirus. This virus is known to cause mild infections prevalently in neonates and children, however, sometimes infections by this virus can cause severe hepatitis which can lead to death ${ }^{20}$.

In the south-western parts of India like Kerala and Karnataka this virus has been known to cause acute flaccid paralysis and has become an upcoming prob$\mathrm{lem}^{21}$.

\section{Chikungunya virus}

Chikungunya virus is a positive single-stranded RNA virus belonging to the alphavirus genus of Togaviridae family. It is transmitted zoonotically by vector mosquitoes of the genus Aedes ${ }^{22}$.

Molecular diagnosis of samples from various patients showed a prevalence of Chikungunya virus infections in Kerala ${ }^{23}$.

\section{Human Adenovirus}

Human Adenoviruses are a group of double-stranded enveloped DNA viruses of the Adenoviridae family known for causing respiratory tract infections ${ }^{24}$.

Prevalence of Human adenovirus B and C was found in the Alappuzha region of Kerala on analyzing samples from patients with flu-like symptoms ${ }^{25}$.

\section{Measles}

Measles virus is an enveloped negative singlestranded RNA virus belonging to the Paramyxoviridae family ${ }^{26}$.

An outbreak of measles occurred in a fisherman community of Kerala. 43 out of the 215 studied children had a history of measles. Moreover, the community was at high risk due to the lack of vaccination owing to poor awareness and living conditions ${ }^{27}$.

\section{Hepatitis A}

Hepatitis A is an enveloped positive single-stranded RNA virus from the Picornaviridae family of viruses. This virus is transmitted by contaminated food and water $^{28}$.

A Hepatitis A outbreak in the Kollam district of Kerala in 2013 was attributed to occur due to the contamination of drinking water from a common source ${ }^{29}$.

\section{Dengue Virus}

Dengue virus is an enveloped single-stranded RNA virus from the Flaviviridae family. It is a zoonotic vector-borne disease transmitted by mosquitoes of the genus Aedes ${ }^{30}$.

Dengue can manifest itself clinically as Dengue hemorrhagic fever and dengue shock syndrome. Both the clinical variants have been quite prevalent in the state of Kerala. Hundred people tested positive for dengue after analysis of serum samples taken from 120 suspected dengue patients in northern Kerala. Moreover, this study showed the presence of multiple serotypes of the dengue virus ${ }^{31}$.

\section{Bacterial diseases in Kerala reported over the past five years}

Over the past five years, there have been very few reports of bacterial diseases as compared to viral diseases in Kerala.

Most of the reported cases of bacterial infections in the state of Kerala are as Urinary and reproductive tract infections. The prevalence of urinary tract infections was observed to be more prevalent among women than in men from the various published studies $^{32-34}$. Both gram-negative and gram-positive bacteria are attributed to be responsible for the urinary tract infections. However, it was noted that there was a higher prevalence of gram-negative bacteria in the isolates taken from urinary tract infections ${ }^{34}$. Some of the most prevalent bacteria causing urinary tract infections in Kerala are Escherichia coli, Klebsiella spp., Citrobacter spp., Enterobacter spp ., Pseudomonas spp., Acinetobacter spp. , Staphylococcus spp. and Proteus spp. ${ }^{32,34}$. 


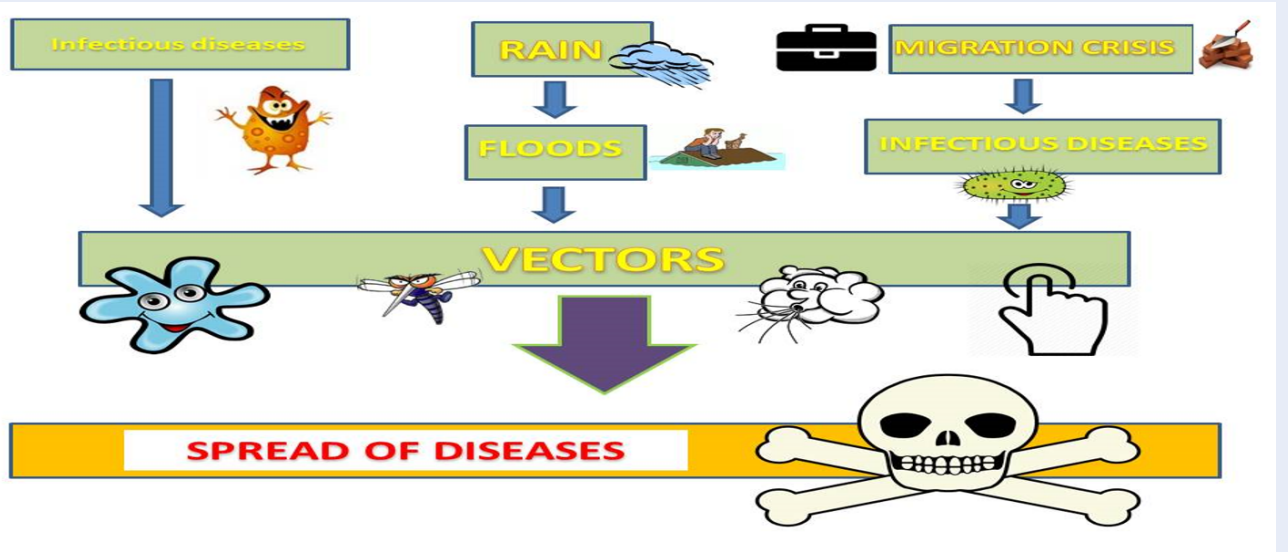

Figure 2: A brief representation of the effects of the various factors on the population health in Kerala.

\section{Migration crisis and its repercussions}

Migration has been a major problem for the state of Kerala for a long period. Most of the migrants are workers from the northern states who live and survive in poor conditions. The migration not only affects the socioeconomic conditions but also contributes to the accumulation of infectious tropical diseases from the northern parts of the country. Various tropical diseases like lymphatic filariasis, leishmaniasis and other vector-borne diseases like malaria are quite prevalent diseases in the northern part of the country. A study on various migrant workers showed the prevalence of infectious diseases like malaria and filariasis in the migrants ${ }^{35}$.

\section{Meteorological calamity in Kerala and its implication}

Heavy rainfall from the $1^{\text {st }}$ to $19^{\text {th }}$ of August in the year 2018 led to devastating floods in the state of Kerala. This heavy rainfall has led to the death of a lot of people as well as the displacement of homes of many others. As reported by the article these floods were triggered as a result of the poor reservoir management in the state. Kerala's Alappuzha district has been one of the primary places affected by the flood ${ }^{36}$.

\section{METHODS}

The Scopus and Google scholar databases were searched using combinations of various keywords. The documents pertaining to factors posing a health risk to citizens were selected manually and were used to formulate a logical result.

\section{RESULT}

We can see that most of the diseases are highly communicable in the state of Kerala. These infections

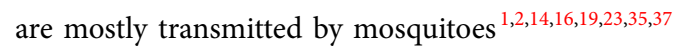
water $^{29,32-34}$, air ${ }^{3,12,25,27}$ and direct and indirect con$\operatorname{tact}^{1,2,4,27,32-34}$ Figure 2. Many of the diseases are observed to occur in the rural areas and the poorer sections of the society who usually live in poor living conditions, don't have proper access to healthcare facilities and also lack the awareness of getting rid of these diseases ${ }^{8,27,29,33,35}$. These communities can act as an epicenter for the spread of communicable diseases in Kerala. Moreover, migration has also led to an increase in the variety of infectious diseases ${ }^{35}$ and can cause multiple problems in the future.

Due to the recent heavy floods, it can be hypothesized that there is a proliferation in the number of waterborne pathogens that were already present in the state of Kerala. Moreover, it can be said that due to the excessive flooding there is an increase in the stagnant water which is a breeding ground of zoonotic vectors like mosquitoes ${ }^{38}$. As most of the diseases were mosquito-borne and waterborne we can see the longlasting effect that these floods may have left on the state.

\section{DISCUSSION}

Although the management of public health in Kerala has been idealistic it is important for the improvement of health care facilities in rural areas to prevent a massive outbreak of these infectious diseases ${ }^{39}$. The most important of all the precautions should be creating awareness of the various diseases and its infectious scenarios throughout the state especially the marginalized communities ${ }^{40}$. Frequent health checks in various areas for the mentioned diseases are very important. Although there has been a lot of investment in healthcare facilities in Kerala, there is still 
a lack of specially trained personnel ${ }^{41}$ and hence it is very important to train people working in healthcare facilities. There should also be frequent immunization programs along with pest control of various zoonotic vectors like mosquitoes.

\section{CONCLUSION}

It can be observed from this review that more precautionary measures should be taken so as to prevent a sudden outbreak of infectious diseases in the future especially in the rural districts like Alappuzha.

\section{COMPETING INTERESTS}

None declared.

\section{AUTHORS' CONTRIBUTIONS}

None declared.

\section{ACKNOWLEDGMENTS}

Not applicable.

\section{REFERENCES}

1. Sharma V, Kaushik S, Kumar R, Yadav JP, Kaushik S. Emerging trends of Nipah virus: A review. Reviews in Medical Virology. 2018;• • •:e2010. Available from: DOI:10.1002/rmv.2010.

2. Chattu V, Kumar R, Kumary S, Kajal F, David J. Nipah virus epidemic in southern India and emphasizing "One Health" approach to ensure global health security; 2018. Available from: DOI:10.4103/jfmpc.jfmpc_137_18.

3. Taubenberger JK, Kash JC. Influenza virus evolution, host adaptation, and pandemic formation. Cell Host \& Microbe. 2010;7:440-51. Available from: DOI:10.1016/j.chom.2010.05. 009.

4. Peter S, Balakrishnan A, Potdar VA, Chadha MS, Jadhav SM. An outbreak of influenza $A(H 3 N 2)$ in Alappuzha district, Kerala, India, in 2011. Journal of Infection in Developing Countries. 2015;9:362-7. Available from: DOI:10.3855/jidc.5723.

5. Govindaraj G, Sridevi R, Nandakumar SN, Vineet R, Rajeev $P$, Binu MK. Economic impacts of avian influenza outbreaks in Kerala, India. Transboundary and Emerging Diseases. 2018:65:e361-72. Available from: DOI:10.1111/tbed.12766.

6. Yuen MF, Chen DS, Dusheiko GM, Janssen HL, Lau DT, Locarnini SA. Hepatitis B virus infection. Nature Reviews Disease Primers. 2018;4:18035. Available from: DOI:10.1038/ nrdp.2018.35.

7. Koroglu M, Demiray T, Ozbek A, Guclu E, Karabay O, Altindis M. Nail scissors and fingernails as reservoirs of hepatitis $B$ virus DNA: role of nail scissors in household transmission of hepatitis B virus. American Journal of Infection Control. 2018;46:793-7. Available from: DOI:10.1016/j.ajic.2017.12. 009.

8. Kuriakose M, Ittyachen AM. An Investigation into the High Prevalence of Hepatitis B in a Rural Area of Kerala State, India: Hypothesis on Chrysops sp. (Diptera: Tabanidae) Transmission. BioMed Research International. 2018;2018:4612472. Available from: Doi:10.1155/2018/4612472.

9. Taleb SA, Thani AAA, Ansari KA, Yassine HM. Human respiratory syncytial virus: pathogenesis, immune responses, and current vaccine approaches. European Journal of Clinical Microbiology \& Infectious Diseases. 2018;37:1817-27. Available from: DOI:10.1007/s10096-018-3289-4.

10. Rey-Jurado E, Kalergis AM. Immunological features of respiratory syncytial virus-caused pneumonia-implications for vaccine design. International Journal of Molecular Sciences. 2017;18:E556. Available from: DOI:10.3390/ijms18030556.
11. Kutter JS, Spronken MI, Fraaij PL, Fouchier RA, Herfst S. Transmission routes of respiratory viruses among humans. Current Opinion in Virology. 2018;28:142-51. Available from: DOI:10.1016/j.coviro.2018.01.001.

12. Patil SL, Balakrishnan A. Genetic characterization respiratory syncytial virus in Kerala, the southern part of India. Journal of Medical Virology. 2017;89:2092-7. Available from: DOI:10. 1002/jmv.24842.

13. Ahlers LR, Goodman AG. The Immune Responses of the Animal Hosts of West Nile Virus: A Comparison of Insects, Birds, and Mammals. Frontiers in Cellular and Infection Microbiology. 2018;8:96. Available from: DOI:10.3389/fcimb.2018 00096.

14. Balakrishnan A, Thekkekara RJ, Tandale BV. Outcomes of West Nile encephalitis patients after 1 year of West Nile encephalitis outbreak in Kerala, India: A follow-up study. Journal of Medical Virology. 2016;88:1856-61. Available from: DOI:10.1002/ jmv.24545.

15. Anukumar B, Sapkal GN, Tandale BV, Balasubramanian R, Gangale D. West Nile encephalitis outbreak in Kerala, India, 2011. Journal of Clinical Virology. 2014;61:152-5. Available from: DOI:10.1016/j.jcv.2014.06.003.

16. Balakrishnan A, Thekkekare RJ, Sapkal G, Tandale BV. Seroprevalence of Japanese encephalitis virus \& West Nile virus in Alappuzha district, Kerala. The Indian Journal of Medical Research. 2017;146:S70-5. Available from: DOI:10.4103/ijmr. IJMR $1638 \_15$

17. Yun SI, Lee YM. Early Events in Japanese Encephalitis Virus Infection: viral Entry. Pathogens (Basel, Switzerland). 2018;7:68 Available from: DOI:10.3390/pathogens7030068.

18. Oliveira AR, Cohnstaedt LW, Cernicchiaro N. Japanese Encephalitis Virus: Placing Disease Vectors in the Epidemiologic Triad. Annals of the Entomological Society of America. 2018; • •. Available from: DOI:10.1093/aesa/say025.

19. Shah SZ, Jabbar B, Ahmed N, Rehman A, Nasir H, Nadeem S. Epidemiology, Pathogenesis, and Control of a Tick-Borne Disease- Kyasanur Forest Disease: Current Status and Future Directions. Frontiers in Cellular and Infection Microbiology. 2018;8:149. Available from: DOI:10.3389/fcimb.2018.00149.

20. Koestner W, Spanier J, Klause T, Tegtmeyer PK, Becker J, Herder V. Interferon-beta expression and type I interferon receptor signaling of hepatocytes prevent hepatic necrosis and virus dissemination in Coxsackievirus B3-infected mice. PLoS Pathogens. 2018;14:e1007235. Available from: DOI:10.1371/ journal.ppat.1007235.

21. Laxmivandana R, Cherian SS, Yergolkar P, Chitambar SD. Genomic characterization of coxsackievirus type B3 strains associated with acute flaccid paralysis in south-western India. The Journal of General Virology. 2016;97:694-705. Available from: DOI:10.1099/jgv.0.000391.

22. Singh A, Kumar A, Yadav R, Uversky VN, Giri R. Deciphering the dark proteome of Chikungunya virus. Scientific Reports. 2018;8:5822. Available from: DOI:10.1038/s41598-018-23969

23. Dayakar S, Goud IK, Pillai H, Remadevi V, Dharmaseelan S, Nair RR. Molecular Diagnosis of Chikungunya virus (CHIKV) and Dengue virus (DENV) and its concomitant circulation in South Indian population. Virology Reports. 2014;5:56-62. Available from: DOI:10.1016/j.virep.2015.05.001.

24. Dou Y, Li Y, Ma C, Zhu H, Du J, Liu H. Rapid diagnosis of human adenovirus $\mathrm{B}, \mathrm{C}$ and $\mathrm{E}$ in the respiratory tract using multiplex quantitative polymerase chain reaction. Molecular Medicine Reports. 2018;18:2889-97. Available from: DOI:10.3892/mmr. 2018.9253.

25. Thounaojam AD, Balakrishnan A, Mun AB. Detection and molecular typing of human adenoviruses associated with respiratory illnesses in Kerala. Japanese Journal of Infectious Diseases. 2016;69:500-4. Available from: DOI:10.7883/yoken. JJID.2015.414.

26. Bhattacharjee S, Yadava PK. Measles virus: background and oncolytic virotherapy. Biochemistry and Biophysics Reports. 
2018;13:58-62. Available from: DOI:10.1016/j.bbrep.2017.12. 004.

27. Nujum ZT, Varghese S. Investigation of an outbreak of measles: failure to vaccinate or vaccine failure in a community of predominantly fishermen in Kerala. Journal of Infection and Public Health. 2015;8:11-9. Available from: DOI: 10.1016/j.jiph.2014.07.013.

28. Lemon SM, Ott JJ, Damme PV, Shouval D. Type A viral hepatitis: A summary and update on the molecular virology, epidemiology, pathogenesis and prevention. Journal of Hepatology. 2017;• • •:S0168-8278(17)32278-X. Available from: DOI:10.1016/j.jhep.2017.08.034.

29. Rakesh P, Sherin D, Sankar H, Shaji M, Subhagan S, Salila S. Investigating a community-wide outbreak of hepatitis a in India. Journal of Global Infectious Diseases. 2014;6:59-64. Available from: Doi:10.4103/0974-777x.132040.

30. Padmalal G, Pankaj G, Jennifer P, Ananda W, Suranjith LS. Dengue Viral Infection. Indian Journal of Psychiatry. 2013;55:135-9. Available from: DOI:10.1136/pgmj.2004. 019638.

31. Reddy MN, Dungdung R, Valliyott L, Pilankatta R. Occurrence of concurrent infections with multiple serotypes of dengue viruses during 2013-2015 in northern Kerala, India. PeerJ. 2017;5:e2970. Available from: DOI:10.7717/peerj.2970.

32. Chandrasekhar D, Dollychan A, Roy BM, Cholamughath S, Parambil JC. Prevalence and antibiotic utilization pattern of uropathogens causing community-acquired urinary tract infection in Kerala, India. Journal of Basic and Clinical Physiology and Pharmacology. 2018;29:671-7. Available from: DOI: 10.1515/jbcpp-2018-0015.

33. Thomas MA, Narayan P. Reproductive tract infections: attitude and barriers among marginalized fisher women in Kerala, South India. Health Care for Women International. 2017;38:361-78. Available from: Doi:10.1080/07399332.2017. 1279616.
34. Rahiman OMF, Balasubramanian T, Kumar $\mathrm{P}$, Ashif CM, Shejina $M$. Prevalence of urinary tract infections and its etiological agents among pregnant women in Malabar region of Kerala. International Journal of Pharmaceutical Sciences Review and Research. 2015;34:202-9.

35. George S, Joy TM, Kumar A, Panicker KN, George LS, Raj M Prevalence of Neglected Tropical Diseases (Leishmaniasis and Lymphatic Filariasis) and Malaria Among a Migrant Labour Settlement in Kerala; 2018. Available from: DOI:10.1007/ s10903-018-0767-9.

36. Padma TV. Mining and dams exacerbated devastating Kerala floods. Nature. 2018;561:13-14.

37. Balasubramanian R, Nikhil TL. Effects of rainfall and salinity increase on prevalence of vector mosquitoes in coastal areas of Alappuzha district, Kerala. Journal of Environmental Biology. 2015;36:1325-8.

38. Wright LD, D'Elia CF, Nichols CR. Impacts of Coastal Waters and Flooding on Human Health BT - Tomorrow's Coasts: Complex and Impermanent; 2019. Available from: Doi:10.1007/978-3319-75453-6_10.

39. Lakshminarayanan S. Role of government in public health: current scenario in India and future scope. Journal of Family \& Community Medicine. 2011;18:26-30. Available from: Doi: 10.4103/1319-1683.78635.

40. Funk S, Gilad E, Watkins C, Jansen VA. The spread of awareness and its impact on epidemic outbreaks. Proceedings of the National Academy of Sciences of the United States of America. 2009;106:6872-7. Available from: DOI:10.1073/pnas. 0810762106.

41. James PT, Kunoor A, Rakesh PS. Awareness of health care workers, patients and visitors regarding air borne infection control - A descriptive study from a Tertiary Care Centre in Kerala, southern India. The Indian Journal of Tuberculosis. 2018;65:168-71. Available from: DOI:10.1016/j.ijtb.2017.08. 028 . 